\title{
Mortality in the rockpool shrimp Palaemon elegans following long-term exposure to low doses of the anti-parasitic drug teflubenzuron
}

\author{
Ole B. Samuelsen* ${ }^{*}$ Aoife E. Parsons, Ann-Lisbeth Agnalt, Tore Tjensvoll, \\ Bjørn T. Lunestad, Rita Hannisdal
}

Institute of Marine Research, PO Box 1870 Nordnes, 5817 Bergen, Norway

\begin{abstract}
Anti-parasitic drugs used to control sea lice infestations in the salmonid aquaculture industry are a growing environmental concern due to their potential impacts on non-target crustacean species. This study examined the lethal effects of teflubenzuron, a common in-feed pharmaceutical drug used on Norwegian salmon farms, on a non-target species, rockpool shrimp Palaemon elegans, following an extended exposure period. The standard daily dose for treating salmon is $10 \mu \mathrm{g}$ teflubenzuron $\mathrm{g}^{-1}$ fish. Adult shrimp were fed 1 of 6 low doses of teflubenzuron $(0$, $0.0025,0.005,0.05,0.094,0.188$ and $1.88 \mu^{-1} g^{-1}$ ) twice a week for a period of $66 \mathrm{~d}$. Cumulative mortality reached $15,27,82$ and $100 \%$ amongst shrimp exposed to the highest treatment groups $\left(0.05,0.094,0.188\right.$ and $1.88 \mu \mathrm{g} \mathrm{g}^{-1}$, respectively). Cumulative mortality amongst shrimp exposed to the 2 lowest teflubenzuron doses and control feed was low $(5 \%)$. Dose response curves based on measured concentrations within the shrimp were used to calculate a series of lethal threshold concentrations $\left(\mathrm{LC}_{\mathrm{x}}\right)$. The $\mathrm{LC}_{5}, \mathrm{LC}_{50}$ and $\mathrm{LC}_{90}$ concentrations of teflubenzuron causing low, median and high levels of mortality in rockpool shrimp were estimated to be 1.2, 18.4 and $150.6 \mathrm{ng} \mathrm{g}^{-1}$, respectively. These concentrations are similar to those reported in wild crustacean species, including shrimp species in the vicinity of Norwegian fish farms, both during and after teflubenzuron medication, suggesting that exposure to low doses of this compound can pose a significant risk to wild shrimp populations.
\end{abstract}

KEY WORDS: Shrimp · Teflubenzuron · Mortality · Aquaculture $\cdot$ Salmon farming $\cdot$ Sea lice

\section{INTRODUCTION}

Salmon lice Lepeophtheirus salmonis (Krøyer, 1837) are small marine ectoparasites that feed on mucous, blood and skin of Atlantic salmon Salmo salar and sea trout Salmo trutta. If present in sufficient numbers, salmon lice may cause large-scale mortalities as a result of osmotic stress and secondary infections caused by bacterial and viral pathogens (Burka et al. 2012). Salmon lice infestations are therefore considered a major problem for the Atlantic salmon aquaculture industry in Europe and North America

\footnotetext{
${ }^{*}$ Corresponding author: ole.samuelsen@hi.no
}

(Costello 2006, 2009, Burka et al. 2012). In addition to reducing the general welfare of the farmed fish, salmon lice cause significant economic loss due to reduced growth, increased mortality, downgrading of flesh quality and the cost of delousing treatments (MacKinnon 1997). Furthermore, excessive numbers of adult lice in the vicinity of salmon farms increase the number of free-swimming larvae in the surrounding waters and consequently have a negative impact on wild populations of sea trout and migrating wild post-smolts of Atlantic salmon (Wagner et al. 2008, Costello 2009, Skaala et al. 2014).

(C) The authors 2020. Open Access under Creative Commons by Attribution Licence. Use, distribution and reproduction are unrestricted. Authors and original publication must be credited. 
Several anti-parasitic agents are currently in use for delousing farmed fish; these compounds are either dissolved in water and used in bath treatments or administered orally via the feed. The in-feed drugs used in Norway are the flubenzurons (teflubenzuron, diflubenzuron) and emamectin-benzoate. Flubenzurons act by interfering with the synthesis of chitin in the salmon lice and are effective against all stages of lice that undergo moulting, including the larval and pre-adult stages (Branson et al. 2000, Ritchie et al. 2002, Campbell et al. 2006). Teflubenzuron is administered via medicated pellets containing $2 \mathrm{~g}$ active compound per $\mathrm{kg}$ feed, and the recommended dosing regime is $10 \mathrm{mg} \mathrm{kg}^{-1}$ fish, daily for $7 \mathrm{~d}$. The bioavailability of teflubenzuron in Atlantic salmon is low $(\sim 10 \%)$, the metabolism minimal, and the elimination pathway is via liver and bile to the intestine (Anon 1999). Therefore, most of the drug is released from the fish as the parent compound during medication and shortly after treatment (Anon 1999). Solubility of teflubenzuron in water is low $\left(0.0094 \mathrm{mg} \mathrm{l}^{-1}\right.$ at $20^{\circ} \mathrm{C}$ ), and the substance associates readily with particles rich in organic content (Marsella et al. 2000). It is, therefore, reasonable to suggest that teflubenzuron enters the environment bound to excess feed and faecal particles. Indeed, a preliminary study analysing faecal material from Atlantic salmon undergoing medication with teflubenzuron showed concentrations more than twice the initial concentration in the medicated feed (O. B. Samuelsen unpubl. data). Teflubenzuron residues have been detected in several species of wild fauna in the vicinity of fish farms, including polychaete worms, crustaceans and fish (Langford et al. 2014, Samuelsen et al. 2015), and in species inhabiting the intertidal zone, such as the amphipod Gammarus locusta and the blue mussel Mytilus edulis (Langford et al. 2014). Consequently, there is growing concern about the potential impacts of teflubenzuron exposure on non-target marine crustaceans. The acute toxicity of teflubenzuron has previously been examined in both marine and terrestrial arthropods (Coppen \& Jepson 1996 a,b, Koyanagi et al. 1998, Abo-Elghar et al. 2004, Medeiros et al. 2013). Indeed, in our previous work, both lethal and non-lethal effects of teflubenzuron on juvenile European lobster Homarus gammarus were observed following oral administration of the drug (10 and $20 \mathrm{mg} \mathrm{kg}^{-1}$ lobster) for $7 \mathrm{~d}$ (Samuelsen et al. 2014). In two similar studies, oral administration of diflubenzuron (600 mg kg-1 feed) also caused lethal effects in larvae and adult deepwater shrimp Pandalus borealis following intermittent dosing for $14 \mathrm{~d}$ (Bechmann et al. 2017, 2018). In these studies, the medication periods were short and diflubenzuron doses were high. Since the half-life of teflubenzuron in marine sediment was estimated to range between 115 and 170 d (Langford et al. 2014, Samuelsen et al. 2015), low doses of teflubenzuron are likely to be available for an extended period. Indeed, low concentrations of teflubenzuron were detected in deepwater shrimp and Norway lobster Nephros norwegicus collected in the vicinity of a Norwegian salmon farm 8 mo post-treatment with teflubenzuron (Samuelsen et al. 2015). To date there is limited information available on the toxicity of low doses of teflubenzuron to marine crustaceans following longterm exposure.

The aim of this study was to examine the lethal effect of orally administered teflubenzuron on adult rockpool shrimp Palaemon elegans offered low doses of the drug over an extended period. To do this, shrimp were fed teflubenzuron-medicated feed twice a week for $66 \mathrm{~d}$, the proportion of dead shrimp was recorded to produce a dose-response curve, and a series of lethal threshold concentrations $\left(\mathrm{LC}_{\mathrm{x}}\right)$ were estimated. Rockpool shrimp are a common species found along the coast of the western Atlantic, from Scotland and Norway to Mauritania, as well as the entire Mediterranean Sea and the Black Sea (Reuschel et al. 2010). They are typically found in rockpools or sandy bottoms covered with algae and eelgrass in the tidal zone. In Norway, rockpool shrimp are common in marine areas with aquaculture facilities and therefore are likely to be exposed to chemical agents used for salmon delousing.

\section{MATERIALS AND METHODS}

\subsection{Animal collection and maintenance}

Adult rockpool shrimp were captured in a large basin at the Institute of Marine Research (IMR) field station at Parisvatnet, outside Bergen, Norway. The distance from the field station to the nearest commercial salmon farm is ca. $6 \mathrm{~km}$. The captured shrimp were transferred to the IMR facility in Bergen and initially placed indoors in $2 \mathrm{~m}^{3}$ tanks supplied with ambient seawater $\left(13^{\circ} \mathrm{C}\right)$ at a flow rate of $\sim 101 \mathrm{~min}^{-1}$. Prior to the experiment, shrimp were moved into individual $171 \mathrm{~cm}^{3}$ white PVC plastic compartments $(7.0 \times 3.5 \times 7.0 \mathrm{~cm})$ and randomly divided into 7 groups of 60 to 80 individuals. Each group was placed in a separate $2 \mathrm{~m}^{3}$ tank, supplied with ambient seawater under the same conditions $\left(13^{\circ} \mathrm{C}\right.$, flow rate $101 \mathrm{~min}^{-1}$ ). The individual compartments had 
perforated floors $(2.5 \mathrm{~mm}$ in diameter) to ensure adequate water flow. The shrimp were fed commercially produced $2 \mathrm{~mm}$ marine pellets (Skretting, Norway) and natural feed such as blue mussel Mytilus edulis. The shrimp were allowed to acclimatise and adapt to pelleted feed for $3 \mathrm{wk}$ prior to the initiation of medication. The mean shrimp total length ( $\mathrm{n}=60)$ was $40.8 \pm 13.9 \mathrm{~mm}$ and mean shrimp weight was $0.80 \pm 0.30 \mathrm{~g}$.

\subsection{Teflubenzuron exposure}

Following acclimatisation, teflubenzuron-medicated feed was orally administered to the shrimp at 1 of 6 dose levels $(0,0.0025,0.005,0.05,0.094,0.188$ and $1.88 \mathrm{\mu g} \mathrm{g}^{-1}$ shrimp) in order to generate cumulative mortality curves. The dose range was selected to encompass concentrations causing 0 and $100 \%$ mortality, based on preliminary experiments (O. B. Samuelsen unpubl. data). The highest dose corresponded to $18.75 \%$ of the daily dose given to Atlantic salmon during medication $\left(10 \mu \mathrm{g} \mathrm{g}^{-1}\right)$. Six groups, each containing 60 shrimp, were given medicated feed, and 1 group, containing 80 shrimp, was given non-medicated feed. Each treatment group was assigned to separate water tanks $\left(2 \mathrm{~m}^{3}\right)$ supplied with running seawater $\left(10 \mathrm{l} \mathrm{min}^{-1}\right)$ at a temperature of $13^{\circ} \mathrm{C}$. Each shrimp was fed 1 pellet (mean $\pm \mathrm{SD}$ weight $=24.4 \pm 2.1 \mathrm{mg}$ ) twice a week for $66 \mathrm{~d}$. The medicated feeds were customised to a $0.80 \mathrm{~g}$ individual and made by homogeneously mixing the appropriate amount of teflubenzuron with $1 \mathrm{~g}$ glucose. Using a few drops of herring oil and gentle shaking, the drug was coated on batches of $50 \mathrm{~g}$ pellets.

Mortality was monitored daily, and dead shrimp were removed and stored at $-18^{\circ} \mathrm{C}$ for further analysis. After $66 \mathrm{~d}$, the study was terminated, and a subset of individuals from each group was frozen and kept at $-18^{\circ} \mathrm{C}$ for further analysis. $\mathrm{LC}_{\mathrm{x}}$ values were calculated based on mortality after $66 \mathrm{~d}$ of teflubenzuron medication and were determined and reported based on measured teflubenzuron concentrations in the shrimp.

\subsection{Teflubenzuron residues: chromatographic analysis}

Accumulation of teflubenzuron in whole shrimp was determined in 10 to 15 shrimp per dosing group and 28 shrimp in the control group.

The preparation of solutions and samples was performed as described by Olsvik et al. (2015), with some modifications. Briefly, whole shrimp were homogenized using a whirl mixer and teflubenzuron was extracted from the homogenate using acetone. Diflubenzuron-d4 was used as internal standard and added to the homogenate prior to extraction. As rockpool shrimp are low in lipid content, the analytical step of removing fat using heptane, described in Olsvik et al. (2015), was not included here. The extracts were purified using an automated solid phase extraction technique (ASPEC). Quantification was performed using an Agilent 1290 LC-system (Agilent Technologies) coupled with an Agilent 6460 triple quadrupole mass spectrometer (Agilent Technologies). The instrument was equipped with an electrospray ionization (ESI) source operated in a negative mode. The analytes were separated by a reverse phase Agilent stable bond C18-column $(150 \mathrm{~mm} \times 2.1 \mathrm{~mm}$ i.d. $1.8 \mu \mathrm{m}$ particle size) (Agilent Technologies) using a $0.4 \mathrm{ml} \mathrm{min}^{-1}$ flow. The mobile phase was a mixture of acetonitrile and water. Chromatography was performed using a stepwise gradient: $0-0.2 \mathrm{~min}, 20 \%$ acetonitrile; $3.0 \mathrm{~min}, 98 \%$ acetonitrile; 3.1-5.0 $\mathrm{min}$, $20 \%$ acetonitrile. All gradient steps were linear. The retention time for teflubenzuron and diflubenzuron$\mathrm{d} 4$ were 2.94 and $2.53 \mathrm{~min}$, respectively. The analyte and internal standard were detected in the multiple reaction monitoring mode (MRM). The mass to charge $(\mathrm{m} / \mathrm{z})$ ratios used were previously described in Olsvik et al. (2015). The following ion source parameters were used: sheat gas temperature: $310^{\circ} \mathrm{C}_{i}$ sheat gas flow: $111 \mathrm{~min}^{-1}$; nebulizer pressure: 45 psig; drying gas temperature: $320^{\circ} \mathrm{C}$ irying gas flow: $101 \mathrm{~min}^{-1}$; capillary voltage: $3500 \mathrm{~V}$; nozzle voltage: $500 \mathrm{~V}$. Procedural blank, matrix blank, matrix-matched calibration curve and controls were prepared for each series. The limit of quantification (LOQ) was determined to $1.0 \mathrm{ng} \mathrm{g}^{-1}$ and the method was linear $(\mathrm{r}=$ 0.99) over the range studied (1-1500 $\mathrm{ng} \mathrm{g}^{-1}$ ).

\subsection{Statistical analysis}

All statistical analyses were conducted in R (R Studio, 3.4.3) (RStudio Team 2016). $\mathrm{LC}_{\mathrm{x}}$ values and their $95 \%$ confidence intervals (CI) were calculated using generalised linear models (GLMs) with binomial error structures and probit links according to Finney (1971). Residual teflubenzuron concentrations were $\log$ transformed $\left(\log _{10}\right)$ to linearise the data. Data was plotted using the ggplot2 R package (Wickham 2009). The differences between intermolt periods was assessed using a GLM with a Gaussian error structure and inverse link. 


\section{RESULTS}

\subsection{Measured teflubenzuron concentrations}

Following oral administration of teflubenzuron, the mean residue concentrations of teflubenzuron in the shrimps increased successively from $2.0 \mathrm{ng} \mathrm{g}^{-1}$ wet weight (ww) for the lowest dose to $568.4 \mathrm{ng} \mathrm{g}^{-1}$ (ww) for the highest dose (Table 1). The mean teflubenzuron concentration in control shrimp was $0.3 \pm$ $0.2 \mathrm{ng} \mathrm{g}^{-1} \mathrm{ww}$. While the measured concentrations were below the limit of detection $\left(<1 \mathrm{ng} \mathrm{g}^{-1}\right)$ in 25 of 28 control shrimp analysed, low concentrations of teflubenzuron $\left(1.1,2.7\right.$ and $3.8 \mathrm{ng} \mathrm{g}^{-1} \mathrm{ww}$ ) were detected in 3 individuals.

\subsection{Mortality}

For the 2 lowest doses of teflubenzuron, mortality was as low as in the control group (5\%, Table 1). However, mortality increased with increasing doses, reaching $100 \%$ in the high-dosed group (Table 1). Mean ( \pm SE) cumulative mortality amongst shrimp fed control feed was $5.0 \pm 2.5 \%$. The mortality in the groups exposed to the 4 highest doses started between Day 6 and 9 after first feeding. A series of lethal threshold concentrations were estimated based on a dose-response curve with shrimp mortalities and mean measured teflubenzuron concentrations (Fig. 1, Table 2).

Most of the mortality in the high-dosed groups could be related to first moult. Of the rockpool shrimp exposed to teflubenzuron concentrations lower than $0.094 \mathrm{ug} \mathrm{g}^{-1}$, between 60 and $90 \%$ were observed to have moulted at least once, and 70 individuals were noted to have moulted twice. In these 70 individuals, the intermoult period was $25.1 \pm$ 5.7 d. There was no significant difference in the

Table 1. Mortality and measured teflubenzuron concentrations (mean $\pm \mathrm{SE}$ ) in rockpool shrimp following a $66 \mathrm{~d}$ oral administration period. ww: wet weight

\begin{tabular}{|lcr|}
\hline $\begin{array}{c}\text { Administered } \\
\text { dose }\left(\mu \mathrm{g} \mathrm{g}^{-1}\right)\end{array}$ & $\begin{array}{c}\text { Measured concen- } \\
\text { tration }\left(\mathrm{ng} \mathrm{g}^{-1} \mathrm{ww}\right)\end{array}$ & \multicolumn{1}{c|}{$\begin{array}{c}\text { Mortality } \\
(\%)\end{array}$} \\
\hline 0 & $0.3 \pm 0.2$ & $5.0 \pm 2.5$ \\
0.0025 & $2.0 \pm 0.6$ & $5.0 \pm 2.8$ \\
0.005 & $1.5 \pm 0.5$ & $5.0 \pm 2.8$ \\
0.05 & $7.3 \pm 1.8$ & $15.0 \pm 4.7$ \\
0.094 & $14.9 \pm 3.5$ & $26.7 \pm 5.8$ \\
0.188 & $27.4 \pm 5.7$ & $81.7 \pm 5.0$ \\
1.88 & $568.4 \pm 142.2$ & $100.0 \pm 0.0$ \\
\hline
\end{tabular}

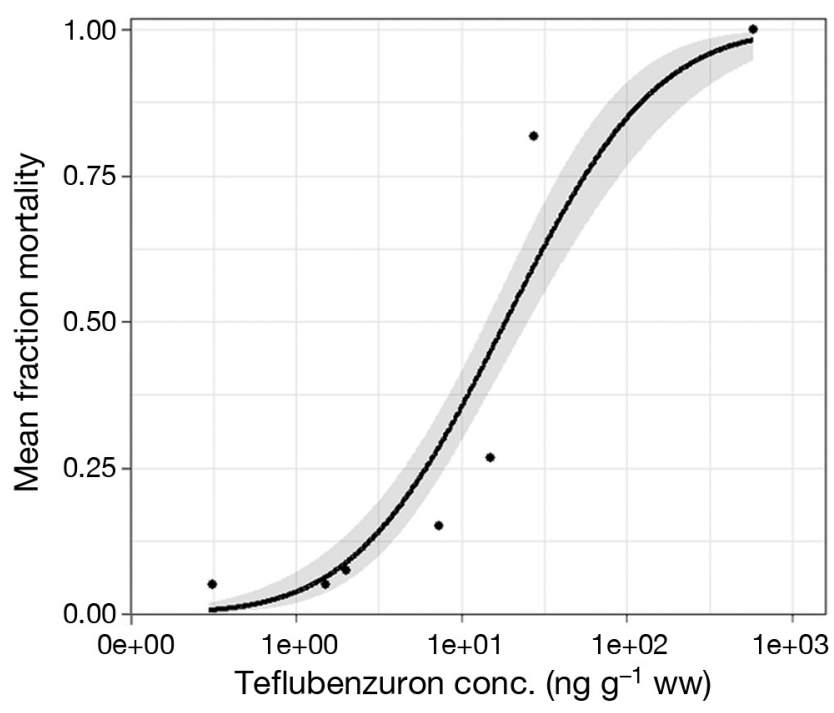

Fig. 1. Toxicity of teflubenzuron to adult rockpool shrimp following a $66 \mathrm{~d}$ oral administration period. Dose-response curve shows mean fractional mortality of shrimp against mean measured concentrations of teflubenzuron and the line represents the best fit model for the data, calculated using a binomial log-probit GLM in R

Table 2. Estimated lethal threshold concentrations (with corresponding $95 \%$ confidence intervals) of teflubenzuron for rockpool shrimp based on mean measured concentrations in shrimp following a $66 \mathrm{~d}$ oral administration period

\begin{tabular}{|lcc|}
\hline $\mathrm{LC}_{\mathrm{x}}$ & ${\text { Threshold }\left(\mathrm{ng} \mathrm{g}^{-1}\right)}$ & $\mathrm{CI}\left(\mathrm{ng} \mathrm{g}^{-1}\right)$ \\
\hline $\mathrm{LC}$ & 0.4 & $(0.1-1.1)$ \\
$\mathrm{LC}^{1}$ & 1.2 & $(0.3-2.5)$ \\
$\mathrm{LC}^{10}$ & 2.3 & $(0.8-4.1)$ \\
$\mathrm{LC}_{25}$ & 6.1 & $(3.2-10.0)$ \\
$\mathrm{LC}_{50}$ & 18.4 & $(11.2-65.7)$ \\
$\mathrm{LC}_{75}$ & 55.7 & $(29.9-167.3)$ \\
$\mathrm{LC}_{90}$ & 150.6 & $(66.2-733.6)$ \\
\hline
\end{tabular}

intermoult periods between treatment groups (GLM, $\left.F_{3,54}=3.9 \mathrm{e}+05, \mathrm{p}=0.38\right)$.

\section{DISCUSSION}

In this investigation, rockpool shrimp were orally administered low doses of teflubenzuron for an extended period in order to mimic a field situation where non-target organisms are exposed to low concentrations of the drug for several months following deployment in nearby aquacultural facilities (Langford et al. 2011, Samuelsen et al. 2014). We show that teflubenzuron induced significant mortality amongst rockpool shrimp following a $66 \mathrm{~d}$ exposure, with an estimated $\mathrm{LC}_{5}, \mathrm{LC}_{50}$ and $\mathrm{LC}_{90}$ of $1.2,18.4$ and 
$150.6 \mathrm{ng} \mathrm{g}^{-1} \mathrm{ww}$ shrimp based on measured internal concentrations. To our knowledge, no lethal threshold concentrations for teflubenzuron have been calculated for marine crustaceans following oral administration to date, therefore, direct comparison of our results with previous studies is not possible. A recent study by Olsvik et al. (2017), however, did examine mortality of rockpool shrimp following a $98 \mathrm{~d}$ exposure to a single low dose of teflubenzuron via diet. In that study, the mean measured concentration of teflubenzuron amongst exposed shrimp was $10 \mathrm{ng} \mathrm{g}^{-1}$ ww shrimp and cumulative mortality reached $50 \%$ by the end of the exposure period (Olsvik et al. 2017). This is in line with the results observed in the present study, where cumulative mortality reached $40 \%$ amongst shrimp with the same internal concentration of teflubenzuron (i.e. $10 \mathrm{ng} \mathrm{g}^{-1} \mathrm{ww}$ shrimp), albeit after a shorter exposure period (66 d). Interestingly, pink shrimp Pandalus montagui orally exposed to low or high doses of teflubenzuron for $46 \mathrm{~d}$ at a water temperature of $9^{\circ} \mathrm{C}$ appear to be slightly less sensitive than the rockpool shrimp examined here. Cumulative mortality amongst exposed pink shrimp was relatively low (25 and $0 \%$, respectively) in groups with mean measured concentrations of teflubenzuron that were higher (71 and $5.8 \mathrm{ng} \mathrm{g}^{-1}$ ww shrimp) than those found in the present study (Olsvik et al. 2019). Chronic exposure to low doses of teflubenzuron has also been shown to be toxic to both terrestrial and aquatic insects, and to aquatic crustaceans exposed via the water (Langford et al. 2011). For example, the $\mathrm{LC}_{50}$ value for teflubenzuron following a $28 \mathrm{~d}$ exposure was $220 \mathrm{ng} \mathrm{g}^{-1}$ soil dry weight (dw) in Folsomia candida (collembola) (Campiche et al. 2006), while a 28 d exposure also resulted in significant mortality amongst the aquatic midge Chorominus riparius at concentrations $\geq 100 \mathrm{ng} \mathrm{g}^{-1}$ sediment $\mathrm{dw}$ (Tassou \& Schulz 2011). Furthermore, copepod (Tisbe battagliai) nauplii exposed to environmentally relevant concentrations of teflubenzuron (0 to $320 \mathrm{ng} \mathrm{l}^{-1}$ ) via the water for $7 \mathrm{~d}$ experienced significant mortality (Macken et al. 2015), and the acute no-observedeffect concentration (NOEC) and lowest-observedeffect concentration (LOEC) were $3.2 \mathrm{ng} \mathrm{l}^{-1}$ and $10 \mathrm{ng} \mathrm{l}^{-1}$, respectively.

The accumulated levels of teflubenzuron in rockpool shrimp reported in this study (2 to $568.4 \mathrm{ng} \mathrm{g}^{-1}$ ww) are in line with levels reported earlier for wild crustaceans living in the vicinity of medicated Norwegian fish farms. For example, low levels of teflubenzuron (0.2-11.3 $\mathrm{ng} \mathrm{g}^{-1}$ and $0.5-3.5 \mathrm{ng} \mathrm{g}^{-1} \mathrm{ww}$, respectively) were detected in deepwater shrimp and the amphipod Gammarus locusta collected 1-5 km from farms located along the western and northern Norwegian coastline within 1 mo of administration of medication, while higher levels (43-185.7 $\mathrm{ng} \mathrm{g}^{-1} \mathrm{ww}$ ) were detected in brown crab Cancer pagurus 100-300 $\mathrm{m}$ from the farms (Langford et al. 2014). In another study, teflubenzuron residues were examined in a range of crustacean species sampled within $300 \mathrm{~m}$ of a commercial fish farm along the west coast of Norway (Samuelsen et al. 2015). During the period of medication, the maximum concentrations of teflubenzuron found were $319 \mathrm{ng} \mathrm{g}^{-1} \mathrm{ww}$ in Norway lobster Nephrops norvegicus, $393 \mathrm{ng} \mathrm{g}^{-1} \mathrm{ww}$ in squat lobster Munida sp., $865 \mathrm{ng} \mathrm{g}^{-1} \mathrm{ww}$ in king crab Lithodes maja and $200 \mathrm{ng} \mathrm{g}^{-1}$ ww in deepwater shrimp (Samuelsen et al. 2015). Lower, but still detectable, concentrations were found in many of the sampled species 8 mo after the medication had been terminated. The maximum concentrations measured in shrimp, brown crab, squat lobster and Norway lobster were 16.1, 20.6, 7.5 and $45.2 \mathrm{ng} \mathrm{g}^{-1} \mathrm{ww}_{\text {, respec- }}$ tively (Samuelsen et al. 2015). The teflubenzuron levels in shrimp from these studies are similar to, or higher than, the $\mathrm{LC}_{50}$ values calculated in the present study, highlighting that wild rockpool shrimp living in the vicinity of fish farms using teflubenzuron are at risk of exposure to potentially lethal concentrations of the drug for long periods of time. It is also interesting to note that chronic exposure to low doses of teflubenzuron may cause sub-lethal effects in marine crustaceans. Indeed, morphological deformities, such as cracked walking legs and cloudy eyes, as well as altered metabolomic responses associated with chitin synthesis and energy metabolism, were observed in pink shrimp exposed to sub-lethal doses of teflubenzuron (5.8-71 $\mathrm{ng} \mathrm{g}^{-1}$ ww shrimp) for $46 \mathrm{~d}$ (Olsvik et al. 2019). Furthermore, behavior, learning and activity of juvenile European lobster were altered following a $113 \mathrm{~d}$ exposure to very low levels of teflubenzuron, with measured concentrations $\sim 1 \mathrm{ng} \mathrm{g}^{-1}$ ww lobster in exposed individuals (Cresci et al. 2018). While mortality was the only toxicity endpoint measured in the present study, future work would be well placed in assessing the sub-lethal effects of teflubenzuron exposure on shrimp and other decapods, both in laboratory and field-based settings.

Since teflubenzuron targets chitin synthesis and induces mortality in connection with moulting, the duration of this study was designed to include at least one moult for every individual. Based on 70 individuals from the control group and the groups exposed to the 3 lowest doses of teflubenzuron, the intermoult period for rockpool shrimp at $13^{\circ} \mathrm{C}$ was $25.1 \pm 5.7 \mathrm{~d}$. Exposure to low doses of teflubenzuron had no sig- 
nificant effect on the length of the intermoult period. Comparing our results with those presented in Yazdani et al. (2010), it is clear that water temperature is an important regulator of the intermoult period, which varied from $25.1 \mathrm{~d}$ at $13^{\circ} \mathrm{C}$ (this study) to less than $9 \mathrm{~d}$ at $24^{\circ} \mathrm{C}$ (Yazdani et al. 2010).

Here we have shown that chronic exposure to environmentally relevant concentrations of teflubenzuron was lethal to rockpool shrimp under laboratory conditions. While it could be possible to extrapolate our results to other crustacean species, sensitivities to pesticides and other environmental pollutants can differ widely even within taxonomic groups. Therefore, further research into the toxicity of teflubenzuron on numerous non-target crustacean species is desirable in order to facilitate robust environmental risk assessments for this compound in the Norwegian marine environment.

Acknowledgements. Thanks to Eva Farestveit, Jan Per Pedersen and Joachim Nordbø for excellent technical assistance. Funding for this work was provided by the Institute of Marine Research (Bergen, Norway), project 14907: Environmental effects of anti sea-lice drugs. This study was approved by the National Animal Research Authority (NARA) in Norway and was carried out in accordance with The Code of Ethics of the World Medical Association for animal experiments.

\section{LITERATURE CITED}

Abo-Elghar GE, El-Sheikh AE, El-Sayed FM, El-Maghraby HM, El-Zun HM (2004) Persistence and residual activity of an organophosphate, pirimiphos-methyl, and three IGRs, hexaflumuron, teflubenzuron and pyriproxyfen, against the cowpea weevil, Callosobruchus maculatus (Coleoptera: Bruchidae). Pest Manag Sci 60:95-102

Anon (1999) The European Agency for the Evaluation of Medical Products (EMEA), Veterinary Medicines Evaluation Unit, teflubenzuron summary report (2), EMEA/ MRL/547/99-FINAL

Bechmann RK, Lyng E, Berry M, Kringstad A, Westerlund S (2017) Exposing Northern shrimp (Pandalus borealis) to fish feed containing the antiparasitic drug diflubenzuron caused high mortality during moulting. J Toxicol Environ Health A 80:941-953

Bechmann RK, Lyng E, Westerlund S, Bamber S and others (2018) Early life stages of Northern shrimp (Pandalus borealis) are sensitive to fish feed containing the antiparasitic drug diflubenzuron. Aquat Toxicol 198:82-91

Branson EJ, Rønsberg SS, Ritchie G (2000) Efficacy of teflubenzuron (Calicide R) for the treatment of sea lice, Lepeophtheirus salmonis (Krøyer 1838), infestations of farmed Atlantic salmon (Salmo salar L.). Aquacult Res 31: 861-867

Burka JF, Fast MD, Revie CW (2012) Lepeophtheirus salmonis and Caligus rogercresseyi. In: Woo PTK, Buchmann K (eds) Fish parasites-pathobiology and protection. CABI, Wallingford, p 350-370
Campbell PJ, Hammell KL, Dohoo IR, Ritchie G (2006) Randomized clinical trial to investigate the effectiveness of teflubenzuron for treating sea lice on Atlantic salmon. Dis Aquat Org 70:101-108

* Campiche S, Becker-van Slooten K, Ridreau C, Tarradellas J (2006) Effects of insect growth regulators on the nontarget soil arthropod Folsomia candida (collembola). Ecotoxicol Environ Saf 63:216-225

Coppen GDA, Jepson PC (1996a) Comparative laboratory evaluation of the acute and chronic toxicology of diflubenzuron, hexaflumuron and teflubenzuron against II instar desert locust (Schistocerca gregaria) (Orthoptera: Acrididae). Pestic Sci 46:183-190

Coppen GDA, Jepson PC (1996b) The effects of the duration of exposure on the toxicity of diflubenzuron, hexaflumuron and teflubenzuron to various stages of II instar Schistocerca gregaria. Pestic Sci 46:191-197

Costello MJ (2006) Ecology of sea lice parasitic on farm and wild fish. Trends Parasitol 22:475-483

Costello MJ (2009) How sea lice from salmon farms may cause wild salmonid declines in Europe and North America and be a threat to fishes elsewhere. Proc R Soc B 276: 3385-3394

Cresci A, Samuelsen OB, Durif CMF, Bjelland RM, Skiftesvik AB, Browman HI, Agnalt AL (2018) Exposure to teflubenzuron negatively impacts exploratory behavior, learning and activity of juvenile European lobster ( $\mathrm{Ho}$ marus gammarus). Ecotoxicol Environ Saf 160:216-221

Finney DJ (1971) Probit analysis, 3rd edn. Cambridge University Press, Cambridge

Koyanagi T, Morita M, Fujii Y (1998) Synthesis and insecticidal activity of alkylated $N$-benzoyl- $N$-phenylureas and their toxicity to aquatic invertebrate. J Pestic Sci 23: $250-254$

Langford KH, Øxnevad S, Schøyen M, Thomas KV (2011) Environmental screening of veterinary medicines used in aquaculture, diflubenzuron and teflubenzuron and their toxicity. Report no. 1086/2011. Norwegian Climate and Pollution Agency, Oslo (in Norwegian with English summary)

炎Langford KH, Øxnevad S, Schøyen M, Thomas KV (2014) Do antiparasitic medicines used in aquaculture pose a risk to the Norwegian aquatic environment? Environ Sci Technol 48:7774-7780

*Macken A, Lillicrap A, Langford K (2015) Benzoylurea pesticides used as veterinary medicines in aquaculture: risks and developmental effects on non-target crustaceans. Environ Toxicol Chem 34:1533-1542

MacKinnon BM (1997) Sea lice: a review. World Aquac 28: 5-10

Marsella AM, Jaskolka M, Mabury SA (2000) Aqueous solubilities, photolysis rates and partition coefficients of benzoylphenylurea insecticides. Pest Manag Sci 56:789-794

*Medeiros LS, Souza JP, Winkaler EU, Carraschi SP, Cruz C, Souza-Júnior SC, Machado-Neto JG (2013) Acute toxicity and environmental risk of teflubenzuron to Daphnia magna, Poecilia reticulata and Lemna minor in the absence and presence of sediment. J Environ Sci Health B 48:600-606

* Olsvik PA, Samuelsen OB, Agnalt AL, Lunestad BT (2015) Transcriptional responses to teflubenzuron exposure in European lobster (Homarus gammarus). Aquat Toxicol 167:143-156

Olsvik PA, Lunestad BT, Agnalt AL, Samuelsen OB (2017) Impact of teflubenzuron on the rockpool shrimp (Palae- 
mon elegans). Comp Biochem Physiol C Toxicol Pharmacol 201:35-43

Olsvik PA, Aulin M, Samuelsen OB, Hannisdal R, Agnalt AL, Lunestad BT (2019) Whole-animal accumulation, oxidative stress, transcriptomic and metabolomic responses in the pink shrimp (Pandalus montagui) exposed to teflubenzuron. J Appl Toxicol 39:485-497

Reuschel S, Cuesta JA, Schubart CD (2010) Marine biogeographic boundaries and human introduction along the European cost revealed by phylogeography of the prawn (Palaemon elegans). Mol Phylogenet Evol 55:765-775

Ritchie G, Rønsberg S, Hoff K, Branson E (2002) Clinical efficacy of teflubenzuron (Calicide) for the treatment of Lepeophtheirus salmonis infestations of farmed Atlantic salmon Salmo salar at low water temperatures. Dis Aquat Org 51:101-106

RStudio Team (2016) RStudio: integrated development environment for R. RStudio, Boston, MA

Samuelsen OB, Lunestad BT, Farestveit E, Grefsrud ES and others (2014) Mortality and deformities in European lobster (Homarus gammarus) juveniles exposed to the antiparasitic drug teflubenzuron. Aquat Toxicol 149:8-15

Editorial responsibility: Dror Angel,

Haifa, Israel
Samuelsen OB, Lunestad BT, Hannisdal R, Bannister R and others (2015) Distribution and persistence of the antisealice drug teflubenzuron in wild fauna and sediments around a salmon farm, following a standard treatment. Sci Total Environ 508:115-121

* Skaala Ø, Kålås S, Borgstrøm R (2014) Evidence of salmon lice-induced mortality of anadromous brown trout (Salmo trutta) in the Hardangerfjord, Norway. Mar Biol Res 10:279-288

Tassou KT, Schulz R (2011) Two-generation effects of the chitin synthesis inhibitor, teflubenzuron, on the aquatic midge Chironomus riparius. Ecotoxicol Environ Saf 74: 1203-1209

*Wagner GN, Fast MD, Johnson SC (2008) Physiology and immunology of Lepeophtheirus salmonis infections of salmonids. Trends Parasitol 24:176-183

Wickham H (2009) ggplot2: elegant graphics for data analysis. Springer-Verlag, New York, NY

Y Yazdani M, Taheri M, Seyfabadi J (2010) Effect of different salinities on survival and growth of prawn, Palaemon elegans (Palaemonidae). J Mar Biol Assoc UK 90: 255-259

Submitted: June 13, 2019; Accepted: November 6, 2019

Proofs received from author(s): January 16, 2020 